\title{
A REPRESENTAÇÃO DO ATO DE FUMAR NO PROCESSO DE CONSTRUÇÃO DO ETHOS
}

\author{
Hilton Castelo*
}

Resumo: $O$ objetivo deste artigo é analisar imagens do enunciador e do co-anunciador, em um discurso de natureza não-verbal que tenha o cigarro como elemento comunicacional emblemático, sustentando-se na sintaxe do ver, conforme Landowski, e na teoria do ethos, na perspectiva de Eggs, Amossy e Maingueneau. Para tanto, a partir de foto jornalística veiculada numa coluna social do jornal Folha de S.Paulo, discutem-se os regimes de visibilidade, a construção do ethos e sua força comunicacional, a cena da enunciação, para, enfim, analisar o ato de fumar em um ethos específico.

Palavras-chave: Regimes de visibilidade; ethos; cena da enunciação; ato de fumar.

Abstract: This article's main purpose is to analyze images of the enunciating and the co-announcer in a non-verbal speech that have the cigarette as the emblematic element, as seen in Landowski, in the theory of ethos, and also in the perspective of Eggs, Amossy and Maingueneau. Having that in mind, starting by a journalistic photo published by "Folha de S.Paulo" newspaper, the modes of visibility are discussed, and so the construction of ethos and its communicational strength, and the scene of enunciation, for finally, analyze the act of smoking in a specific ethos.

Keywords: Modes of visibility; ethos; scene of enunciation; act of smoking.

\section{Introdução}

A imagem é exemplar. Trata-se de uma foto jornalística tirada por João Sal, veiculada na Ilustrada da Folha de S. Paulo, na coluna social assinada por Mônica Bergamo, em 15 de novembro de 2006 (Figura 1). O quadro em que a imagem foi inserida está dividido em duas colunas. Do lado esquerdo, visão do leitor, ocupando um terço do espaço, uma coluna na cor branca traz em sua parte superior um quadro menor, sutilmente inclinado, na cor preta, que apresenta a legenda da foto vazada em texto branco. Do lado direito, a segunda coluna apresenta-nos a foto propriamente dita, cuja

\footnotetext{
* Mestrando em Comunicação e Linguagens (Universidade Tuiuti do Paraná)
}

INTRATEXTOS, Rio de Janeiro. vol. 2, nº 1, pp. 20 - 32, 2010. 
composição vertical divide a imagem em dois blocos, cada com dois elementos: na parte de cima, um relógio de parede, modelo bastante convencional, e um aviso público; na parte inferior, a imagem de uma mulher e botões de emergência para casos de incêndio.

O quadro-legenda, destacado em sua coluna pela ausência de outros elementos gráficos e pelo contraste com a cor de fundo, cujo formato remete à idéia de etiqueta da foto, traz a seguinte informação:

"FUMACINHA [grifo do jornal] A cantora Rita Lee faz piada com o aviso "Não Fume" no camarim do show de Maria Bethânia, na noite da última sexta-feira, no Tom Brasil Nações Unidas."

FIGURA 1: Rita Lee em camarim de show.

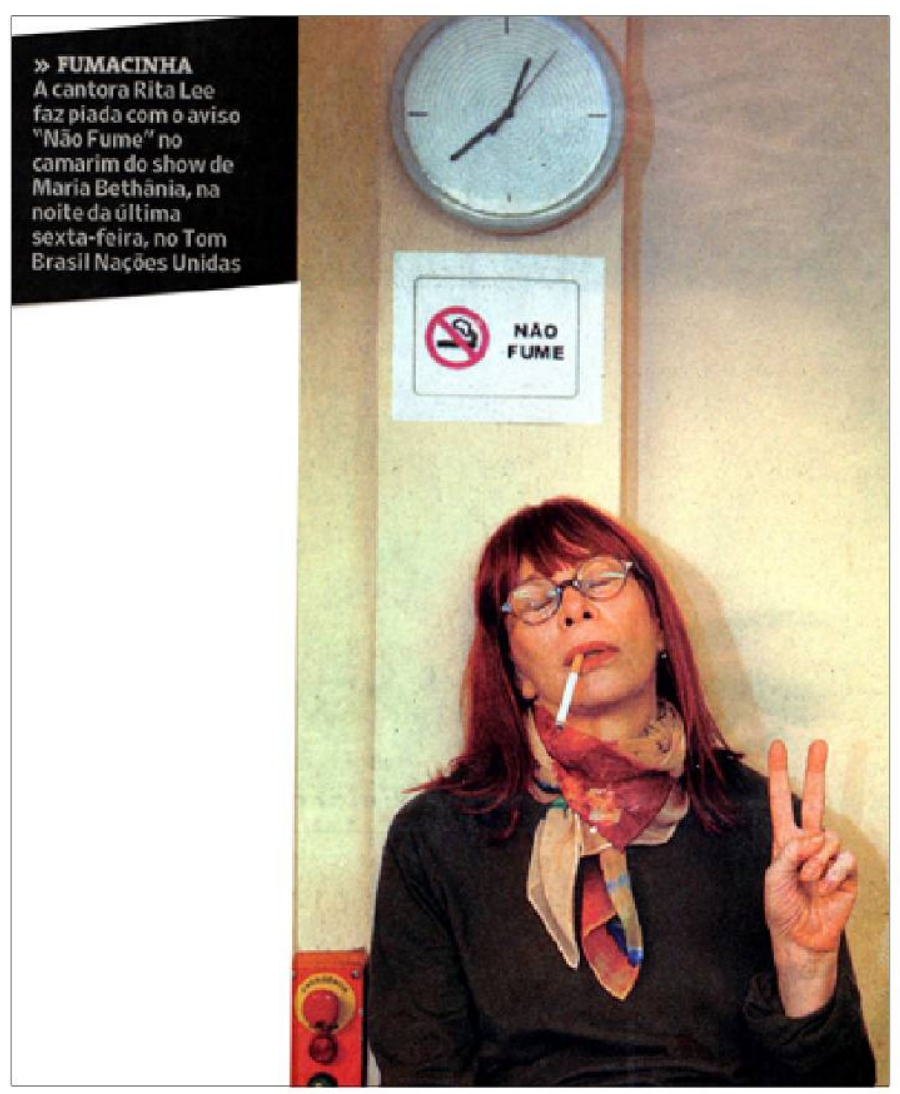

Fonte: Folha de S.Paulo, 15/11/2006.
Os ponteiros do relógio indicam vinte minutos para a uma hora da manhã. Abaixo do relógio, vê-se o que aparenta ser uma folha comum de papel sulfite colada na parede, e, nela, dois signos de tamanhos semelhantes, um verbal e outro não-verbal, com a informação redundante de ser proibido o uso de cigarros.

A mulher, Rita, veste blusa cor grafite de manga comprida. Ao redor do pescoço, echarpe de estampa multicolorida,

combinando com a cor da blusa e com longos cabelos ruivos e lisos que escorrem sobre os ombros, dá a Rita certo clima de modernidade. O corte de cabelo franjado acentua a 
presença dos óculos redondos, já um tanto desproporcional em relação ao tamanho ao rosto. O vermelho forte do batom acentua o tamanho dos lábios.

Rita está com a cabeça levemente inclinada para a esquerda do leitor, encostada contra a parede. A posição do corpo e, principalmente, as dobras na blusa indicam que ela está sentada. Os olhos fechados, detrás dos óculos, denotam a idéia de casualidade, enquanto o braço esquerdo levantado exclui a possibilidade de que ela esteja dormindo.

No canto direito da boca, pendendo para baixo, está um cigarro, ainda pouco consumido pelo fogo, e que vai desafiadoramente de encontro ao aviso "Não fume". Confronto, aliás, que se acentua por um "V" formado pelos dedos de Rita - talvez como sinal de vitória ou da expressão "paz e amor" -, e pelos botões de emergência no canto inferior esquerdo da foto. No conjunto, o registro contundente de um indivíduo que se mostra blasé, indiferente às normas estabelecidas por convenções legais ou sociais.

Quem está na cena enunciativa: Rita Lee, a roqueira, ou Rita Lee Jones Carvalho, uma senhora que, em setembro de 2006, estava a três meses de tornar-se sexagenária? O público ou privado? Em que medida esse ato comunicacional serve para a representação e manutenção de um ethos desejado naquela cena enunciativa?

Está claro que a imagem de Rita Lee veiculada pela Folha de S.Paulo possibilita análise de múltiplas situações comunicacionais, cada qual com suas especificidades e, portanto, de contextos discursivos díspares: do fotógrafo para o jornal; do jornal para um leitor eventual e desinteressado em notícias culturais, do jornal para o leitor contumaz de cadernos de cultura; de Mônica Bergamo para leitores exclusivamente interessados em notícias sociais, de Bergamo para a intelligentsia paulistana; de Rita Lee para os presentes no camarim, da cantora para seus fãs. A este trabalho, consciente de não estar respondendo a todas as possibilidades interpretativas oferecidas pelo objeto, interessa, nesse momento, os dois últimos contextos e seus regimes específicos de visibilidade.

\section{Tornando-se visível}

Landowski (1992, pp. 86-89) constata que os termos de "regime de visibilidade", ao nortear as relações entre o público e o privado, subordinam-se à "sintaxe do ver" e a relações de reciprocidade entre "um que vê" e "outro que é visto" ou, conforme Émile Benveniste, citado por Landowski (1992), num processo no qual 
“Cada membro só descobre seu 'si' no 'entre si'”. Porém, apesar da existência de condicionantes relacionais nos modos de ver e de ser compreendido, o jogo discursivo, em casos de exposição voluntária de figuras públicas, dificilmente ocorre em condições de descontrole.

A foto da cantora em coluna social, veiculada por um periódico sabidamente dirigido a um público de melhor formação cultural, insere-se num jogo discursivo entre sujeitos que comungam interesses socioculturais, num processo de reafirmação de si a partir de expectativas comportamentais de uma platéia. Ao posar para a foto, Rita Lee expõe sua condição de pessoa pública e privada ao julgamento de uma platéia préjulgada pela própria cantora, criando condições para a reafirmação de si a partir de atitudes consideradas previsíveis no Outro. Diferente, portanto, para melhor situar a questão, do caso de um flagrante de paparazzi, em foto tirada às escondidas, revelando o uso pela artista de um cigarro de maconha. Ideia que se sustenta em Michel Pêcheux, citado por Amossy (2005, p. 11), ao observar que, "nas duas pontas da cadeia de comunicação", o emissor A e o interlocutor B compartilham de expectativas imagéticas: “o emissor A faz uma imagem de si mesmo e de seu interlocutor B; reciprocamente, o receptor B faz uma imagem do emissor A e de si mesmo" e, completando com Landowski (1992, pp. 89-90), “dois protagonistas unidos por uma relação de pressuposição recíproca (...) e entre os quais circula o próprio objeto de comunicação". Mas em que medida e especificações modais? É o próprio Landowski quem responde:

Uma vez colocada como necessária e suficiente, a relação mínima constitutiva do ver admite, em níveis mais superficiais, diferentes especificações modais (essencialmente do tipo querer, dever, saber, poder ver), cujo emprego condiciona a maneira como os actantes, no caso os dois agentes - individuais ou coletivos - designados como o que "vê" e o que "é visto", entram em relação. (...) em particular quando (...) necessário atribuir um lugar aos dispositivos de "iluminação" (que "permitem ver") e aos procedimentos de "captação" (que "garantem ser visto"). (LANDOWSKI, 1992, p. 90) 
A partir das especificações modais preconizadas em Landowski, aplicadas graficamente no esquema do quadrado semiótico (Figura 2), percebe-se na foto de João Sal atos comunicacionais que revelam em Rita a tentativa de construção de ethos em situação de publicização de papéis privados.

FIGURA 2: Esquema do Quadrado Semiótico

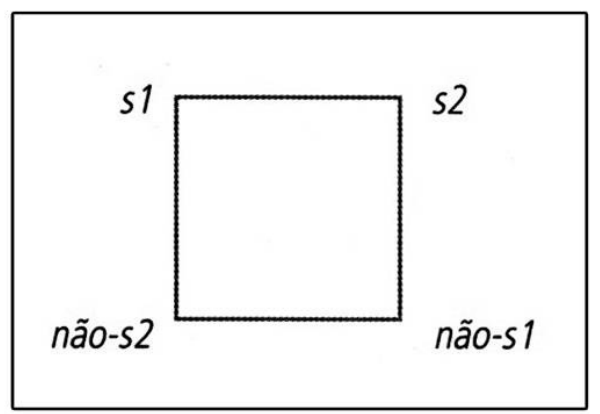

Fonte: VOLLI, 2007, p. 72
O quadrado semiótico (Figura 2), dispositivo lógico aristotélico usado sobretudo pela escola de Greimas, conforme explica Volli (2007, pp. 72-74), é “marcada por oposições estabelecidas e organizadas pelas convenções culturais". Em síntese, de forma breve e superficial: 1) s1 e s2 são contrários (branco e preto, conforme exemplo de Volli); 2) s1 e não-s1, como s2 e não-s2, são contraditórios (branco e não-branco; preto e não-preto); 3) não-s1 e não-s2 são subopostos (não-branco e não-preto). Volli (2007, p. 73) ressalta que os subopostos "podem ter em comum zonas intermediárias". No exemplo do semioticista italiano, o não-branco poderia se entendido como escuro, enquanto o não-preto, claro. Nesse caso, ter-se-ia, em zona comum intermediária, a cor acizentado.

Aplicando o esquema do quadrado semiótico à presença discursiva do ator diante de seu público, Landowski (Figura 3) coloca, na condição de contrários, o "querer ser visto" - a representação pública do artista em cena - ao "querer não ser visto" - a presença do artista, em papel privado, nas coxias, em um momento proposital e desejado de isolamento. Em contradição ao "querer ser visto", situa-se o "não querer ser visto" - a privatização dos papéis públicos, a exemplo do ensaio, do momento de preparação para a encenação. Contradizendo o "querer não ser visto", há a presença do artista no camarim, ainda em momento de representação, porém agora encenando papéis privados, ou, para usar os termos de Landowski, em "publicização" de papéis privados. Como situação(ões) comunicacional(ais) subopostas, em zona intermediária entre o ensaio e o camarim, o "não querer ser visto" e o "não querer não ser visto", ou seja, em termos de Landowski, entre a "privatização dos papéis públicos" e "publicização dos papéis privados". 
FIGURA 3: Presença discursiva de Landowski.

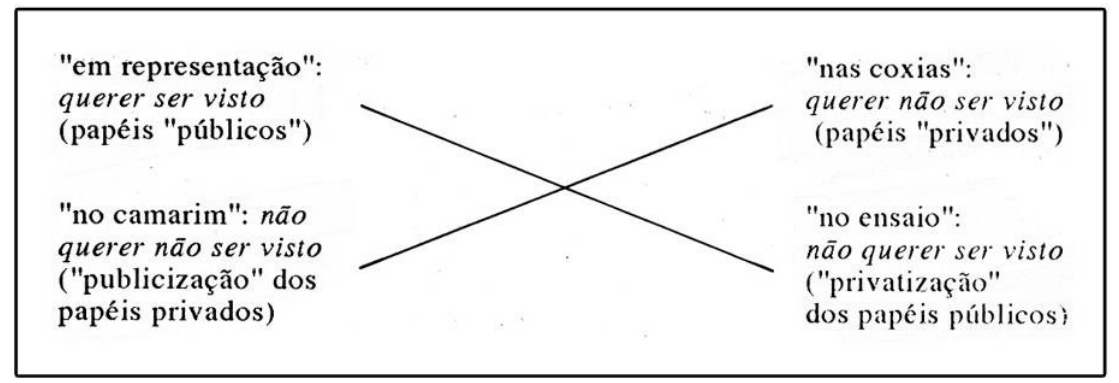

Fonte: LANDOWSKI, 1992, p. 92.

Baixado o pano (terminada a representação), ainda é preciso "representar", não mais, decerto, no palco e para o grande público, mas em outro palco (o camarim) e para um petit comité (os "íntimos", os "admiradores"). Se isso não é mais propriamente "representar" é, pelo menos, o que se chama familiarmente "fazer encenação". (LANDOWSKI, 1992, p. 92)

No camarim do show de Maria Bethânia, ao posar para a coluna de Mônica Bergamo na Folha de S.Paulo, Rita Lee (re)apresenta-se em ato comunicacional de "não querer não ser visto", procurando construir um ethos - um caráter - que ela imagina compatível, desejado e passível de ser compartilhado com um auditório duplamente válido: a dos amigos presentes no camarim e dos fãs leitores do jornal. Como bem observa Maingueneau (2008, p. 29), o ethos traz aos processos de interpretação a ordem da experiência sensível, a partir de modos de dizer que destaque-se - são também modos de ser, aproximando o ethos e seu vínculo com a "reflexividade anunciativa" dos regimes de visibilidade de Landowski.

\section{Imagem de si no discurso}

De que modo Rita Lee constrói-se diante de seu público e como o ato de fumar torna-se representativo para a construção de uma imagem negociada com a platéia no presente no camarim e na situação de leitor do jornal?

Para a construção da própria imagem, ensina Amossy (2005, p. 9), "não é necessário que o locutor faça seu auto-retrato, detalhe suas qualidades nem mesmo que fale explicitamente de si”, baste que tome a palavra, ou, em outros termos, que esteja em ação discursiva, de forma deliberada ou não. É o que basta para o ethos do orador manifestar um tipo social - a partir de gestuais, modos de se expressar - e ter como um 
auditório $^{1}$, um interlocutor e co-autor na produção de significados - como "juiz da conveniência da expressão afetiva do orador" (EGGS, 2005, p. 43).

Ethos, termo advindo da retórica antiga, que, em grego significa personagem, "designa a imagem de si que o locutor constrói em seu discurso para exercer uma influência sobre seu alocutário" (Charaudeau; Maingueneau, 2006, p. 220). Tal imagem, de acordo, com Discini (2008, p. 34) é "o caráter que o orador deve ter" ou - como entendemos ser mais adequado - traços de caráter que o orador deve mostrar ao auditório (pouco importa sua sinceridade) para dar uma boa impressão (...) O orador enuncia uma informação e, ao mesmo tempo, diz: eu sou isto, não aquilo lá" (BARTHES, apud MAINGUENEAU, 2008, p. 13).

Rita Lee está com a palavra na ação discursiva, e, por meio de representações simbólicas, apresenta no camarim, para julgamento do auditório, o que ela imagina ser adequado a um "não querer não ser visto" do ethos de rebeldia. Expressar-se de forma conservadora seria negar o plano de fundo apto a traduzir a condição de roqueira perante o público.

À semelhança de Amossy (2005, p. 31), Maingueneau (2008, pp. 14-18) afirma que o ethos, por sua natureza, encontra-se em plano de fundo da enunciação ${ }^{2}$. Constata ainda que o ethos apresenta-se como comportamento articulador, em nível verbal e nãoverbal, de efeitos multisensoriais em percepções complexas, para um destinatário que tira seu conhecimento do ambiente, em processos interativos, analisáveis e integrados a contextos sócio-históricos. Ao alargar o alcance do ethos para além da retórica tradicional - ou seja, situações de eloqüências, de falas públicas -, Maingueneau o aceita "abarcando todo tipo de texto, tanto os orais como os escritos", além de recobrir não só a dimensão verbal, mas também o conjunto de determinações físicas e psíquicas, a uma corporalidade, situações estereotípicas comportamentais.

Ainda que não haja fala ou, de outra forma, a expressão da palavra oralizada da cantora, o ethos da rebeldia é construído pela dimensão corporal. Concepção apoiada também em Antoine Auchlin (apud MAINGUENEAU, 2008, pp. 16-17), quando este assume o ethos como caráter de concepções variadas entre o mais concreto e o abstrato,

\footnotetext{
${ }^{1}$ Auditório é empregado aqui no sentido de destinatário coletivo idealmente imaginado.

${ }^{2}$ Na definição de (Charaudeau \& Maingueneau, 2006, p. 192), "A enunciação constitui o pivô da relação entre a língua e o mundo: por um lado, permite representar fatos no enunciado, mas, por outro, constitui por si mesma um fato, um acontecimento único definido no tempo e no espaço".
}

INTRATEXTOS, Rio de Janeiro. vol. 2, nº 1, pp. 20 - 32, 2010. 
podendo, assim, ser concebido de modo "singular ou coletivo", "implícito ou visível", “ousado ou convencional", "próximo ou distante", "modesto ou imodesto".

E nesse diálogo entre Rita Lee e seu auditório há um elemento primordial para a construção do ethos da rebeldia: o cigarro dependurado no canto direito da boca. $\mathrm{O}$ cigarro, conforme muito observa Klein (1997, p. 47) - que normalmente é considerado mero acessório do rosto no retrato, com seu papel nem essencial e nem diminuto, de utilidade reservada à esfera incidental do lazer e da distração -, na foto da cantora, porém, desloca-se para lugar diverso: sai da condição de objeto periférico para o centro das atenções, e assume o lugar de elemento emblemático na representação corporal, na construção de um ato comunicacional antes sugerido do que explicitado. Mas por quê? Por que o cigarro, ainda aos olhos de Klein (1997, p. 49) por natureza "tão insignificante e supérfluo, tão frívolo e depreciado, que mal tem uma identidade ou natureza precisa", toma para si tal importância?

Maingueneau constata que o ethos está sempre presente no discurso humano, participando daquilo que é mostrado, mas não é falado explicitamente, porém num limite opaco entre o dito e o sugerido:

O ethos de um discurso resulta da interação de diversos fatores: ethos prédiscursivo, ethos discursivo (ethos mostrado), mas também os fragmentos do texto nos quais o enunciador evoca sua própria enunciação (ethos dito) (...) ou indiretamente, por meio de metáforas ou de alusões a outras cenas da fala, por exemplo. A distinção entre ethos dito e mostrado se inscreve nos extremos de uma linha contínua, uma vez que é impossível definir uma fronteira nítida entre o "dito" sugerido e o puramente "mostrado" pela enunciação. (MAINGUENEAU, 2008, p. 19)

É precisamente no contexto sutil entre o dito e o não dito, na força simbólica das entrelinhas, que o cigarro de Rita Lee encontrará sua força comunicacional. Na história cultural de estilo e fumaça que fez Klein (1997) afirmar que "Cigarros são sublimes", calcado "no glamour que envolve o ato de fumar, ou segurar um cigarro". Ato afiançado por tradições cinematográficas, fotográfica, obras literárias e musicais, representações simbólicas estereotipadas da intelectualidade. Imaginário coletivo, na acepção 
antropológica do termo, e contradições da modernidade refazendo-se como "capital simbólico"3 para a construção de um corpo anunciante na cena de enunciação.

Para Maingueneau (2008, pp. 70-82), o ethos manifesta-se como voz e corporalidade anunciante - seja no sentido físico ou na forma de uma presença qualitativa no espaço social -, resultando da ação mútua de co-anunciadores, ou seja, o destinador e o sujeito ideal, aquele visado pelo destinador, em repertórios que variam de acordo com a especificidade do discurso. Desse modo, o ethos torna-se parte constitutiva de uma cena de enunciação ${ }^{4}$ - constituída por "cena englobante", "cena genérica" e "cenografia" -, afiançada em atos (im)explícitos e presumida como adequada ao discurso e ao contexto.

De acordo com Charaudeau \& Maingueneau (2006, p. 96), "enquanto a 'cena englobante' atribui um sentido pragmático ao tipo de discurso" (exemplo: discurso jornalístico, publicitário, político), e “a 'cena genérica' é definida pelos gêneros de discursos particulares" (exemplo: folheto, libelo, artigo), a "cenografia" é instituída no próprio discurso:

\begin{abstract}
Não empregamos aqui "cenografia" no sentido que tem seu uso teatral, mas dando-lhe um duplo valor: (1) Acrescentando à noção teatral de "cena" a de -grafia, da "inscrição": para além da oposição empírica entre o oral e o escrito, uma enunciação se caracteriza, de fato, por sua maneira específica de inscrever-se, de legitimar-se, prescrevendo-se um modo de existência no interdiscurso; (2) Não definimos a "cena enunciativa" em termos de "quadro", de decoração, como se o discurso se manifestasse no interior de um espaço já construído e independente desse discurso, mas consideramos o desenvolvimento da enunciação como a instauração progressiva de seu próprio dispositivo de fala. (...) apreendida ao mesmo tempo como quadro e como processo. (MAINGUENEAU, 2005, pp. 76-77)
\end{abstract}

A "cenografia", em Maingueneau (2005, p. 77) - assim como o enunciador e o co-enunciador -, é ligada a um momento (cronografia) e a um lugar (topografia), de onde emerge qualquer discurso. Pode-se, portanto, afirmar que a "cenografia" é origem

\footnotetext{
${ }^{3}$ O termo "capital simbólico", da sociologia de Pierre Bourdieu, prevê o uso das regras de conduta como capital mediador para a obtenção de vantagens efetivas nas relações sociais.

${ }^{4}$ Dimensão construtiva do discurso, conforme Charaudeau \& Maingueneau, 2006, p. 95.
}

INTRATEXTOS, Rio de Janeiro. vol. 2, nº 1, pp. 20 - 32, 2010. 
discursiva e legitimadora de enunciado. O leitor do discurso, por isso, não é apenas decodificador de sentido, mas implicado intrinsecamente na "cenografia", constituindose, então, como, nas palavras de Maingueneau (2005, p. 90), “como fiador do mundo representado".

A "cenografia" da cena de enunciação em que se encontra Rita Lee traz, portanto, atos implícitos presumivelmente adequados tanto ao público presente no camarim do show de Maria Bethânia - provável habitué de espaços culturais - quanto ao destinatário do caderno Ilustrada de a Folha de S.Paulo - leitor habituado e receptivo a tais capitais simbólicos. Desse modo, legitimado pelo momento e lugar de onde emerge o discurso, o cigarro, como instrumento de representação social, toma a cena como índice apontando para si próprio. Apontando para a contradição?

\section{O valor indicial do ethos}

Ao contrapor-se o caráter rebelde constituído na imagem de Rita Lee à expressão de rebeldia presente na imagem de Che Guevara ${ }^{5}$ (Figura 4), percebem-se as diferentes formas que o mesmo ethos pode assumir na cena enunciativa.

FIGURA 4: Rita Lee e Che Guevara.

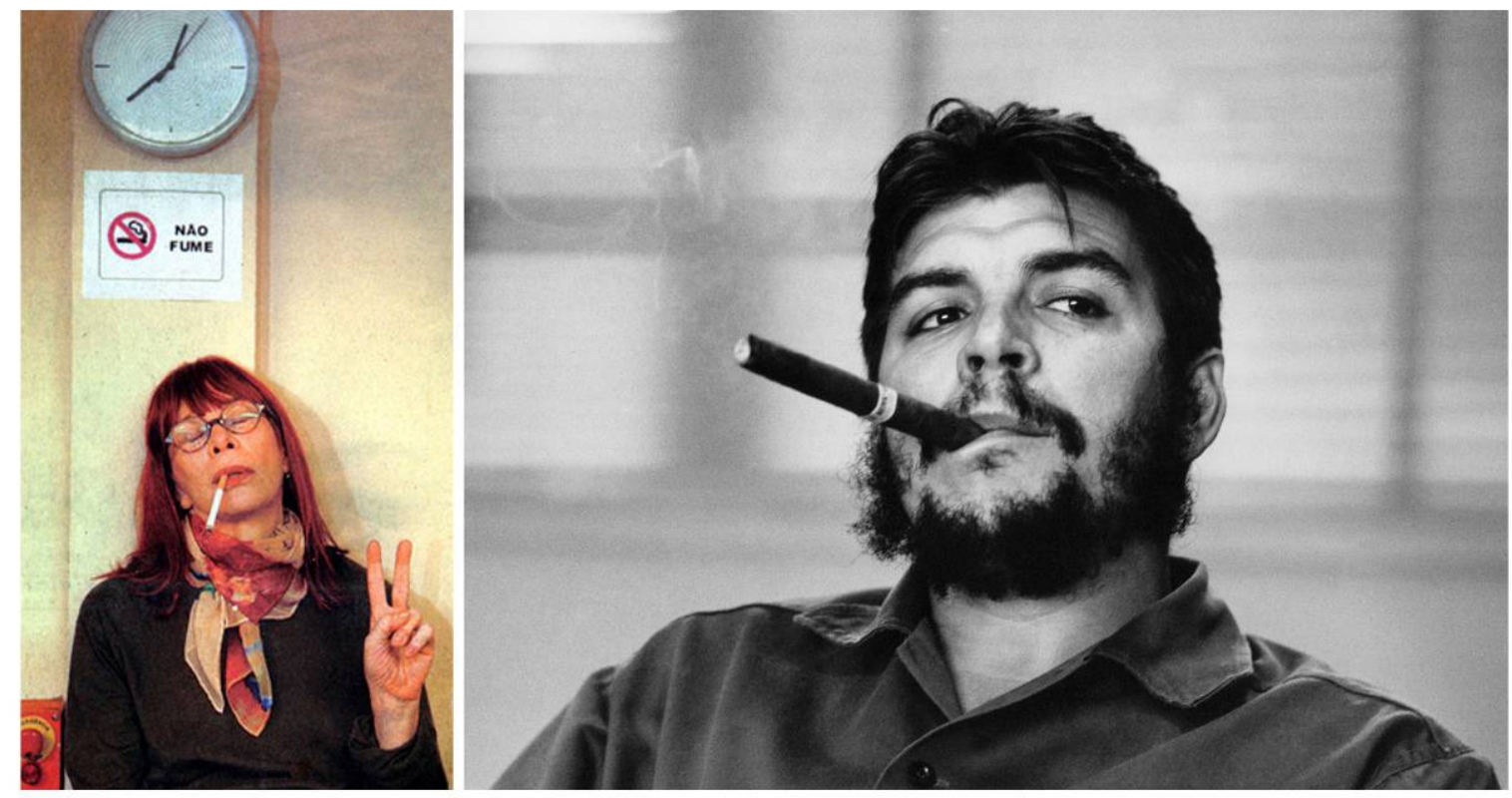

Fonte: detalhe da figura 1 e internet.

\footnotetext{
${ }^{5}$ Disponível em: http://phoenixworks.net/userimages/procart9.htm. Acesso: 27 de junho de 2009.
}

INTRATEXTOS, Rio de Janeiro. vol. 2, nº 1, pp. 20 - 32, 2010. 
Se, em Ernesto Guevara, o ato comunicacional de fumar coopera para construir um ethos da rebeldia como índice de altivez e respeitabilidade, em Rita Lee, por sua vez, o ethos conota humor e cinismo. Ou, de outra forma, o cigarro como corpo discursivo santificado e decaído.

Conforme Klein (1997, p. 46) “o cigarro é (...) uma entidade (...) uma categoria geral das coisas", um índice que "aponta para si mesmo". No caso de Rita Lee - um cigarro respaldado em inúmeras representações cinematográficas e literárias -, que aponta para o ofício de roqueira e tudo o que isso representa no imaginário coletivo desde meados do século passado. Um cigarro que se apaga como cigarro para reencarnar-se em ato comunicacional semelhante a quebrar ou incendiar guitarra no palco, definindo-se, assim, aos olhos do auditório, como "ficção idealizada ou uma ilusão tecnicamente persuasiva." (KLEIN, 1997, p. 47).

O confronto explícito entre Rita Lee e o aviso de "Não fume" torna a cantora porta-voz da intelligentsia contra as limitações governamentais impostas ao ato de fumar em espaços públicos, contra a subordinação do momento histórico-social, um tempo simbolicamente inscrito na imagem pelo relógio na parede, àquilo que se costuma chamar de politicamente-correto. Entretanto, não é a ação de um ethos rebelde panfletário. O corpo largado e relaxado, os olhos fechados, o braço levantado, os dedos em "V", os botões de emergência e, principalmente, o cigarro caído no canto da boca entreaberta, entre lábios exageradamente vermelhos, desvelam um "não querer não ser visto", na acepção de Landowski, de um ethos rebelde burlesco. O que está ali é o tom de galhofa de um Dom Quixote pós-moderno a tentar utilizar sua lança caída contra àquilo que enunciador e co-enunciador apreendido pelo ethos entendem como o ridículo socialmente constituído.

Curioso o fato de a legenda de Mônica Bergamo fazer questão de explicitar que "Rita Lee faz piada com o aviso 'Não Fume' no camarim do show de Maria Bethânia". É como se a colunista, após a inexistência de qualquer problema no camarim, tivesse agora a certeza da existência de um público não compreensível ao ato comunicacional ali implícito. Porém, ao tentar evitar o julgamento de Rita Lee pelo auditório, Bergamo a julga pela redundância entre legenda e o contexto da foto e, ao mesmo tempo, aponta nas entrelinhas o motivo para a condenação. Sutilezas do discurso. 


\section{Considerações finais}

Apesar da cronografia e da topografia situarem a cena enunciativa em espaço privado, o camarim de um show, fica claro que é da figura pública, da roqueira Rita Lee, da "mãe do rock brasileiro"6 que estamos falando. Em situação estabelecida de modo contraditório ao que seria um papel realmente privado, consagra-se aquilo que Landowski chama de "publicização dos papéis privados" ou, em outros termos, de um "não querer não ser visto". Ou seja, outro palco em que Rita Lee faz encenação para um petit comitê formados por íntimos e admiradores.

Os traços de caráter que a cantora mostra ao auditório, implicados numa "cenografia", constroem o ethos rebelde burlesco, no qual a cantora reflete e consagrada um modo de ser - a representação simbólica desejada por ela perante o seu público -, ao mesmo tempo em que procura negar o contrário daquela aparência.

O ethos implicado na cena, construído particularmente pela atuação física de Rita Lee, tem como centro comunicacional o ato de fumar e seus entornos, que leva o leitor do discurso, conforme Maingueneau (2005, p. 90), a não apenas decodificar o sentido, mas também participar do mesmo mundo, como "parceiros dotados de competência correspondente" para jogos ópticos de situações e posições de comunicação (LANDOWSKI, 1992).

O ethos da rebeldia burlesca coloca nas mãos de Rita Lee o "Cetro de Dionísio" e o simbolismo que o ato de fumar, em sua dimensão comunicativa, pode oferecer:

O cigarro é em si mesmo um volume, um livro ou um pergaminho que revela suas associações múltiplas, heterogêneas, discrepantes (...) O cigarro é um tirso, o cetro de Dionísio (...) que representa a intenção poética e o propósito criativo (...) que requer exércitos de romancistas, cineastas, compositores e poetas (KLEIN, 1997, pp. 49-50).

\footnotetext{
${ }^{6}$ Expressão pela qual a cantora Rita Lee é conhecida no meio musical brasileiro, cf. Revista Época On-Line, em http://epoca.globo.com/edic/20000417/cult8.htm, acessada em 27 de junho de 2009.
}

INTRATEXTOS, Rio de Janeiro. vol. 2, nº 1, pp. 20 - 32, 2010. 
Cetro e Dionísio. Bastão de apoio, poder real instintivo e confuso, evanescente, inspiração criadora e compartilhada de um deus profano da alegria e do vinho. E - por que não? - do dionisíaco cigarro.

\section{REFERÊNCIAS BIBLIOGRÁFICAS}

AMOSSY, R. "Da noção retórica de ethos à análise do discurso". In: AMOSSY, R. (org.). Imagens de si no discurso: a construção do ethos. São Paulo: Contexto, 2005.

CHARAUDEAU, P. \& MAINGUENEAU, D. (2006). Dicionário de análise do discurso. 2. ed. São Paulo: Contexto, 2006.

DISCINI, N. "Ethos e estilo". In: MOTTA, A. R. \& SALGADO, L. (orgs.). Ethos discursivo. São Paulo: Contexto, 2008.

EGGS, E. "Ethos aristotélico, convicção e pragmática moderna." In: AMOSSY, R. (org.). Imagens de si no discurso: a construção do ethos. São Paulo: Contexto, 2005.

KLEIN, R. Cigarros são sublimes: uma história cultural de estilo e fumaça. Rio de Janeiro: Rocco, 1997.

LANDOWSKI, E. A sociedade refletida: ensaios de sociossemiótica. São Paulo: EDUC/Pontes, 1992.

MAINGUENEAU, D. “A propósito do ethos.” In: Motta, A. R. \& Salgado, L. (orgs.). Ethos discursivo. São Paulo: Contexto, 2008.

. "Ethos, cenografia, incorporação.” In: AMOSSY, R. (org.). Imagens de si no discurso: a construção do ethos. São Paulo: Contexto, 2005.

VOLLI, U. (2007). Manual de semiótica. São Paulo: Edições Loyola. 